\title{
Immunolocalisation of phosphorylated STAT3, interleukin I I and leukaemia inhibitory factor in endometrium of women with unexplained infertility during the implantation window Evdokia Dimitriadis*1, Andrew M Sharkey², Yee Lee Tan'1, Lois A Salamonsen ${ }^{1}$ and J Robert A Sherwin ${ }^{3}$
}

Address: ${ }^{1}$ Prince Henry's Institute of Medical Research, P.O. Box 5152, Clayton, VIC, 3168, Australia, ${ }^{2}$ Department of Pathology, Tennis Court Road, Cambridge, CB2 1QP. UK and ${ }^{3}$ Department of Obstetrics and Gynaecology, University of Cambridge, The Rosie Hospital, Cambridge, CB2 2SW, UK

Email: Evdokia Dimitriadis* - evdokia.dimitriadis@princehenrys.org; Andrew M Sharkey - as168@cam.ac.uk; Yee Lee Tan - jltan1@yahoo.com; Lois A Salamonsen - lois.salamonsen@princehenrys.org; J Robert A Sherwin - jras100@ hermes.cam.ac.uk

* Corresponding author

Published: 29 November 2007

Reproductive Biology and Endocrinology 2007, 5:44 doi:10.1 186/1477-7827-5-44

This article is available from: http://www.rbej.com/content/5/I/44

(C) 2007 Dimitriadis et al; licensee BioMed Central Ltd.

This is an Open Access article distributed under the terms of the Creative Commons Attribution License (http://creativecommons.org/licenses/by/2.0), which permits unrestricted use, distribution, and reproduction in any medium, provided the original work is properly cited.
Received: 14 September 2007

Accepted: 29 November 2007

\begin{abstract}
Background: Uterine receptivity and embryo implantation are critical in the establishment of pregnancy. The diagnosis of endometrial fertility requires more precise measurements of endometrial receptivity. Interleukin (IL-II) and leukemia inhibitory factor (LIF) are essential for murine implantation and signal via intracellular phosphorylation (p) of STAT3 in the endometrium. Both cytokines are present in the endometrium of women duiring the receptive window. Endometrial IL-I I, IL-I I receptor alpha (IL-I I Ralpha), LIF and PSTAT3 in women with primary unexplained infertility was compared to normal fertile women during the implantation window.

Methods: $\mathrm{LH}$ timed endometrial biopsies $(\mathrm{LH}+6$ to $\mathrm{LH}+10)$ were collected from women with unexplained infertility and normal fertility. PSTAT3, IL-I I, IL-I I Ralpha and LIF production was determined by immunohistochemistry. Staining intensity was determoned by two independent observers blind to the fertility status of the patient from whom the biopsy was taken. Staining intensity and heterogeneity in each of the endometrial compartments (epithelium; stroma, including decidualized stromal cells; and vasculature) was assessed. The Mann-Whitney $U$ test was used to analyze IL-I I, PSTAT3, IL-I I Ralpha and LIF immunostaining intensities in the samples.

Results: IL-I I, IL-I IRalpha and LIF were present predominantly in glandular epithelium, whilst luminal epithelium showed patchy staining. PSTAT3 was present in both glandular epithelium and stroma. IL- I I and PSTAT3 immunostaining was significantly lower in glandular epithelium in infertile women compared to controls $(P<0.05)$ whilst IL-I I Ralpha and LIF staining did not differ.

Conclusion: This is the first demonstration of reduced endometrial PSTAT3 and IL-II in some women with unexplained infertility. This suggests IL-II and PSTAT3 may be involved in the secretory transformation of glandular epithelium during receptivity. Reduced IL-I I production and STAT3 phosphorylation may contribute to unexplained infertility in some women.
\end{abstract}




\section{Background}

Embryo implantation into the uterus is a critical step in the establishment of pregnancy and failure of this process is a major cause of infertility in women [1].

Endometrium is receptive to the embryo for a short timeperiod, after exposure to $17-\beta$-estradiol followed by progesterone [2]. Embryo transfer studies in women and primates have identified the phase of uterine receptivity, the 'window of implantation', between post-ovulatory days 5-10 [3] following the luteinizing hormone ( $\mathrm{LH}$ ) surge. Implantation of the embryo between post-ovulatory days 8-10 has a high chance of resulting in a successful pregnancy [4]. Unexplained infertility accounts for approximately $30 \%$ of all infertility $[5,6]$. Defective uterine receptivity is thought to be a primary cause of unexplained infertility. Unexplained or primary infertility is likely due to multiple defects as it has been associated with numerous molecular and cellular disturbances in the endometrium $[7,8]$.

Interleukin-11 (IL-11) and LIF belong to the interleukin-6 (IL-6) family of cytokines whose members exhibit pleiotropy and redundancy, with many overlapping functions [9]. IL-11 binds to IL-11 receptor (IL-11 R $\alpha$ ) and initiates signalling whilst LIF signals by binding to the specific LIF receptor $\alpha$ (LIFR). Each ligand-receptor complex forms a hetero-dimer with gp130, the common transmembrane signal transducer. In the endometrium, intracellular signalling occurs via activation of the janus kinase (JAK)/signal transducers and activators of transcription (STAT) pathway [10-12]. IL-11 and LIF are part of an exclusive group of genes that are essential for implantation in mice [13]. Both endometrial IL-11 and LIF are obligatory for implantation in mice [14-16]. STAT3 also has an important role in implantation in mice $[10,17]$. Blockade of phosphorylated (p) STAT3 at the time of embryo attachment reduces implantation rates in mice $[18,19]$.

Although the role of LIF in human endometrial receptivity has been previously studied the results are conflicting $[8,20]$. There are very few studies examining the role of IL11 and no studies for pSTAT3 in infertility in women [21]. IL-11, LIF and pSTAT3 are expressed by endometrial, glandular and luminal epithelium in the mid-secretory phase of the menstrual cycle in women [22-25]. Similarly, midsecretory phase luminal and glandular epithelium express gp130, LIFR $\alpha$ and IL-11R $\alpha[22,24,26,27]$. Immunoreactive LIF is reduced in endometrial biopsies from infertile women [28], while uterine flushings contain maximum levels of LIF protein during the mid to late secretory phase of the menstrual cycle [29-31]. In addition, LIF is reduced in uterine flushings from women with primary infertility compared to fertile controls [29-31]. Similarly, IL-11 is present in uterine fluid [32]. These studies suggest IL-11 and LIF are secreted by the uterine glandular epithelium into the uterine lumen where they could act on the blastocyst or the endometrial luminal epithelium to facilitate blastocyst attachment and implantation.

In addition, in some women with endometriosis associated infertility, IL-11 and LIF immunoreactivity are reduced in glandular epithelium suggesting that both cytokines may also contribute to the pathology of infertility of unknown cause [12]. While, IL-11 and LIF expression is spacially and temporally distinct in mice, they are both present in glandular epithelium and utilize similar signal transduction pathways at the time of implantation in women. It is important to determine whether they potentially act in a redundant manner. In a previous study, while LIF production was not different between women with unexplained infertility and normal fertile women, there was reduced secretion of soluble gp130 from endometrial explants. This indicates it is important to also examine IL-11 and LIF's signalling components together with the production of the ligands. pSTAT3 is of particular interest since it has an important role in implantation in mice. There are no studies examining the production of IL-11 and pSTAT3 in endometrium of women with primary unexplained infertility.

We hypothesized that IL-11, IL-11R $\alpha$, LIF and pSTAT3 are dysregulated in endometrium from women with unexplained infertility during the 'window of implantation'. Endometrial protein abundance for IL-11, pSTAT3, IL$11 \mathrm{R} \alpha$ and LIF was compared in women with primary unexplained infertility and normal fertile women.

\section{Methods \\ Participants and endometrial biopsies}

Endometrial biopsies were collected from women with primary unexplained infertility of more than 2 years duration ( $\mathrm{n}=10$, age $25-40 \mathrm{yr}$ ) and fertile age matched controls ( $\mathrm{n}=9$, age 25-40 yr) between days $\mathrm{LH}+6$ to $\mathrm{LH}+10$. All women had regular menstrual cycles of 26-32 days, were not using intra-uterine contraceptives and had not used hormones for at least three months prior to surgery. Women with infertility who had partners with male factor infertility were not included in the study. The women with infertility did not have ovulation or tubal patency defects and endometriosis. All infertile patients and controls had negative laparoscopies. All women biopsied in the secretory phase of the menstrual cycle, performed home urinary LH surge tests and all biopsies were histologically dated according to the Noyes criteria [33]. Written informed consent was obtained from all patients before their operations and protocols were approved by Institutional Ethical committees, namely Southern Health Human Ethical Committee and Addenbrooke's Hospital NHS Trust. Ethical approval was also obtained from 
Southern Health Human Ethics Committee, Melbourne, Australia.

\section{Immunohistochemistry}

Tissues were stained for IL-11 and IL-11R $\alpha$ with mouse anti-huIL-11 (clone 5E3) and mouse anti-hulL-11R (clone 4D12) antibodies (generous gifts from Dr Lorraine Robb) as previously described [23]. Briefly, dewaxed, rehydrated sections were incubated with blocking solution containing 10\% horse serum (Sigma Aldrich Inc. Missouri, USA), 5\% human serum and Tris Buffered saline (TBS) (pH 7.4) for $30 \mathrm{~min}$. Primary antibodies were applied diluted to $5 \mu \mathrm{g} / \mathrm{ml}$ (IL-11) and $2.5 \mu \mathrm{g} / \mathrm{ml}$ (IL$11 \mathrm{R} \alpha$ ) in blocking solution for $18 \mathrm{~h}$ at $4{ }^{\circ} \mathrm{C}$. Antibody localization was detected by sequential application of biotinylated horse anti-mouse IgG (Vector Laboratories, Burlingame, CA, USA) in blocking solution, followed by an avidin-biotin complex conjugated to HRP (Vectastain ABC Elite kit; Vector Laboratories).

LIF protein was immunostained using antiserum against human LIF protein raised in rabbit (AMRAD Pharmacia Biotech, Boronia, Vic., Australia) as previously described [23]. The primary antibody (1:2000) was applied on the tissues for $12 \mathrm{~h}$ at RT. The slides were washed, biotinylated swine anti-rabbit IgG (DAKO, Glostrup, Denmark;) applied, followed by streptavidin-biotin-peroxidase complex (Vector Laboratories Inc., Burlingame, CA, USA) according to the manufacturer's instructions.

Tissues were stained for pSTAT3 as previously described using rabbit polyclonal antibodies raised against human peptides (R\&D Systems Inc.) [12]. Briefly, sections were preincubated with $10 \%$ non-immune horse serum (Sigma-Aldrich, Sydney, Australia), 2\% normal human serum (in-house) in TBS and $0.1 \%$ Tween 20. Primary antibodies were applied overnight $(17 \mathrm{~h})$ at $4{ }^{\circ} \mathrm{C}$ diluted to $4 \mu \mathrm{g} / \mathrm{ml}$ in non-immune block. Detection of positive binding was performed by the sequential application of biotinylated goat anti-rabbit IgG; (Vector Laboratories) and avidin-biotin-peroxidase conjugate (Dako, Glostrup, Denmark).

In all cases the substrate used was diaminobenzidine (DAB) (Zymed, San Francisco, USA). A section from a single block of first trimester decidua was included in each staining run for quality control and an isotype-matched negative control at the same protein concentration as the primary antibody, was included for each tissue. The immunohistochemistry procedure was conducted at least twice for each tissue and each ligand/receptor.

\section{Assessment of immunostaining}

Immunostaining was analyzed semi-quantitatively by two independent observers blind to the fertility status of the patient from whom the biopsy was taken. Staining intensity and heterogeneity in each of the endometrial compartments (epithelium; stroma and vasculature) was assessed and allocated a score between 0 and 3 where numbers represent, 0 : no stain, 1 : faint, 2: moderate and 3 : strong, relative to positive and negative controls.

\section{Statistics}

Results are expressed as mean \pm SEM. The Mann-Whitney U test was used to analyze IL-11, IL-11R $\alpha$ and LIF immunostaining in the infertile and fertile control samples. Differences were considered statistically significant when $P<$ 0.05 .

\section{Results \\ Endometrial IL-I I, IL-I IR $\alpha$ and LIF immunostaining in women with primary infertility and fertile controls between days $\mathrm{LH}+6$ to +10}

IL-11 staining was largely confined to the glandular epithelium in the endometrial tissue (Figure $1 \mathrm{~A}$ and $1 \mathrm{~B}$ ). IL11 immunoreactivity was moderate to high in glandular epithelial cells from all control fertile women and some infertile women (Figure 1A and 1B and Figure 2A). However, mean IL-11 staining in glandular epithelium was consistently more intense in tissues from control women compared to the infertile women $(1.7 \pm 0.2$ vs $1.1 \pm 0.2$ respectively, $\mathrm{P}<0.05)$ (Figure $2 \mathrm{~A}$ ), although there was a clear overlap between the groups. Minimal staining for IL11 was observed in the stromal compartment in tissues from fertile and infertile women (Figure $1 \mathrm{~A}$ and $1 \mathrm{~B}$ ). Seven tissues from both infertile and control fertile women contained luminal epithelium. IL-11 staining in luminal epithelium was low-moderate and did not differ between infertile and control groups (data not shown). There was no correlation with staining intensity and women's age (data not shown).

Similarly, IL-11R $\alpha$ staining in endometrial tissues was present predominantly in glandular epithelial cells (Figure 1C and 1D). While all tissues from control and infertile women stained for IL-11R $\alpha$, the intensity ranged from minimal to high and was not different between infertile and fertile women (Figure 2B). IL-11R $\alpha$ staining was low in stromal and vascular cells in all tissues and did not differ between the groups (data not shown).

LIF staining was maximal in glandular epithelium and minimal in the stromal compartment in the biopsies (Figure $1 \mathrm{E}$ and $1 \mathrm{~F})$. LIF staining intensity in glandular epithelial cells was variable within the tissues from both infertile and fertile women. It ranged from low to maximal and did not differ between the two groups (Figure 2C). 

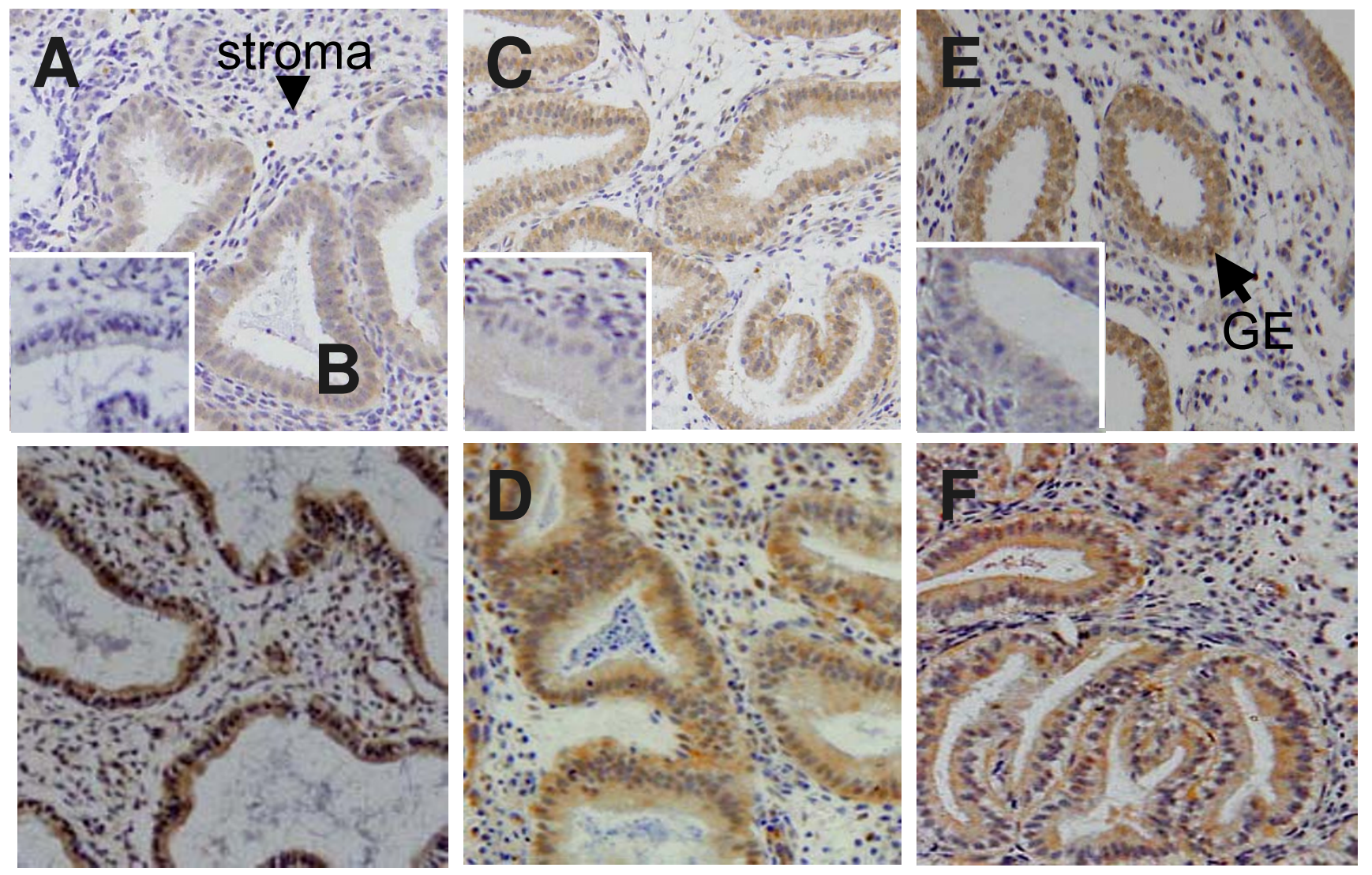

\section{Figure I}

Photomicrographs representing immunostaining for IL- I I, IL- I IR $\alpha$ and LIF of human endometrium from fertile controls and women with primary infertility. Positive staining is shown as brown pigment with blue nuclear hematoxylin counterstain. Magnification $\times 200$. (A-B) IL-I I staining. (A) Day LH+6 tissue from woman with infertility. (B) Day LH+6 tissue from fertile woman. (C-D) IL- I IR $\alpha$ staining. (C) Day LH+8 tissue from woman with infertility. (D) Day LH+8 tissue from control fertile woman. (EF) LIF staining. (E) Day LH+8 tissue from fertile woman. (F) Day LH+8 tissue from infertile woman.

\section{Endometrial pSTAT3 immunostaining in women with primary infertility and fertile controls between days $\mathrm{LH}+6$ to +10}

We aimed to examine whether pSTAT3 was reduced in endometrium of women with infertility compared to normal fertile women. We also aimed to determine whether pSTAT3, IL-11's main down stream target molecule was reduced in the same women that we observed a reduction in IL-11 immunostaining. pSTAT3 staining was present in endometrial glandular epithelium and stroma (Figure 3A-C). pSTAT3 immunoreactivity ranged from absent to moderate in glandular epithelium of infertile women (Figure 3A-B and 4A). Mean pSTAT3 staining in glandular epithelium was consistently more intense in tissues from control women compared to the infertile women $(1.3 \pm$ 0.3 vs $0.4 \pm 0.2$ respectively, $\mathrm{P}<0.05$ ) (Figure $4 \mathrm{~A}$ ). No correlation was found between IL-11 and pSTAT3 staining intensity in the glandular epithelium (data not shown). Minimal to high staining for PSTAT3 was observed in the stromal compartment in tissues from fertile and infertile women and was not different between the groups of women (Figure $3 \mathrm{~A}-\mathrm{C}$ and $4 \mathrm{~A}-\mathrm{B}$ ). Seven out of the ten women with infertility had very low levels of both IL-11 and PSTAT3 protein in the glandular epithelium (data no shown). Seven tissues from both infertile and control fertile women contained luminal epithelium. However, pSTAT3 staining in luminal epithelium was present in one tissue from the infertile group and two tissues from the control group (Figure 3E and 3F)

\section{Discussion}

We demonstrated for the first time that IL-11 and pSTAT3 immunoreactivity in uterine glandular epithelium was decreased in women with unexplained infertility.

We observed a significant decrease in IL-11 and pSTAT3 in uterine glandular epithelium in some women with infertility compared to normal cycling fertile women. Unex- 

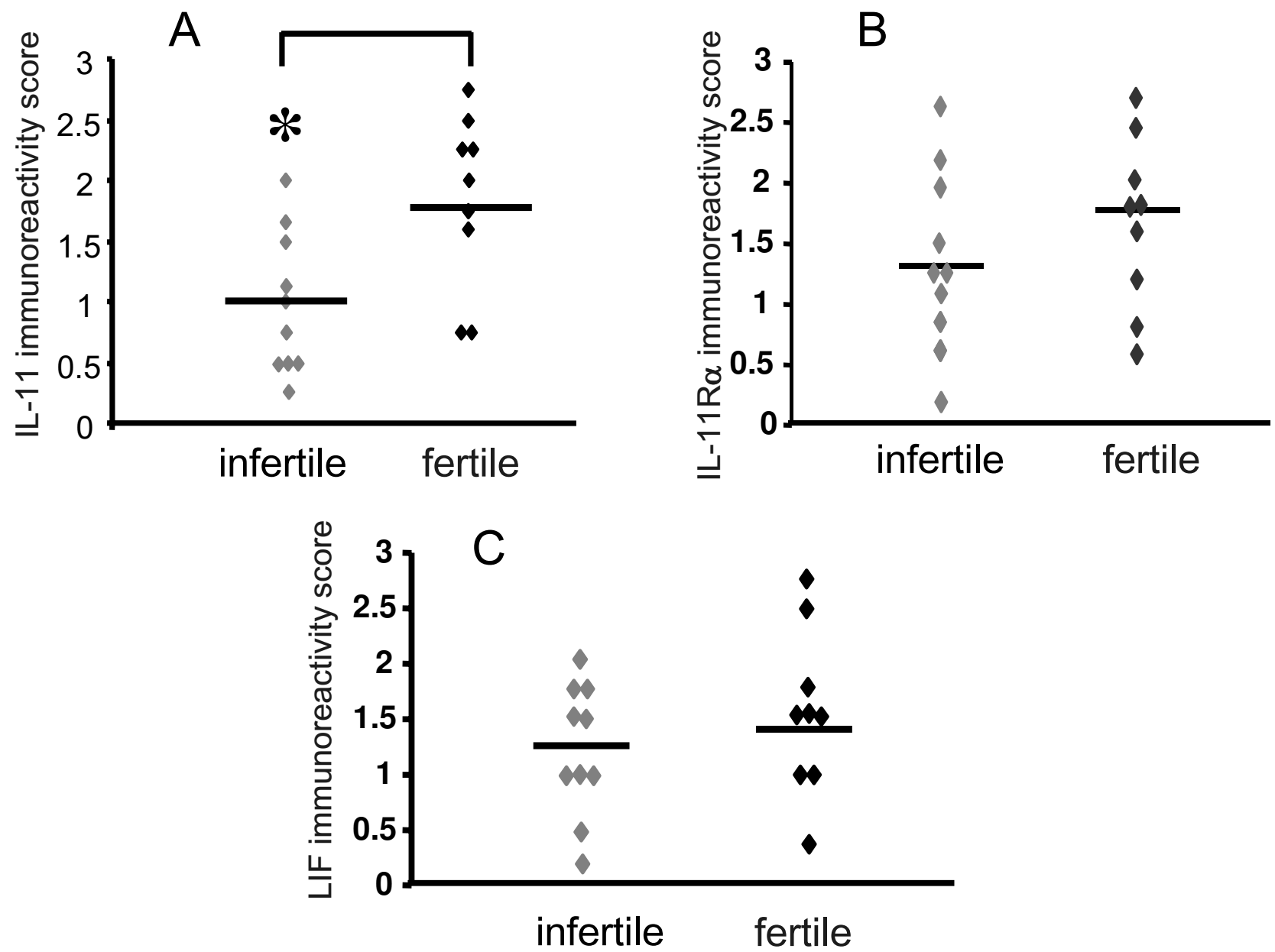

\section{Figure 2}

Immunostaining for IL-I I, IL- I IR $\alpha$ and LIF in endometrial glandular epithelium from normal fertile women and women with primary infertility between days $\mathrm{LH}+6-+10$ of the menstrual cycle. Relative staining intensities are represented as 0 (no staining) to 3 (high). (A) IL- I I staining. (B) IL- I IR $\alpha$ staining (C) LIF staining. Women with primary infertility (infertile) ( $\mathrm{n}=\mathrm{I0}$ ). Control normal fertile women (fertile) $(n=9)$. Individual data shown for each parameter. Bar represents the mean value. $* P<0.05$ compared to fertile control.

plained infertility is likely caused by several defects therefore it is not surprising that we identified cohorts of infertile women with defective IL-11 and pSTAT3 production. IL-11 could be acting on the glandular epithelium to facilitate its secretory transformation. In addition, IL-11 has been identified in the uterine lumen of women [32]. IL-11 present in the uterine lumen could act on the endometrial uterine epithelium to facilitate attachment or adhesion of the blastocyst.

Low glandular pSTAT3 may be due to either reduced STAT3 protein production and/or factors that stimulate
STAT3 phosphorylation. IL-11 and LIF are known to signal via STAT3 in endometrium $[10,25]$. Interestingly, glandular epithelium from women with infertility that had low IL-11 staining did not consistently have low pSTAT3 staining. LIF protein levels did not correlate with pSTAT3 levels in glandular epithelium. This suggests factors other than these cytokines regulate STAT3 protein activation. It is also plausible that IL-11 and LIF stimulate pSTAT3 in glandular epithelium but the levels of STAT3 protein may be low in glandular epithelium of some infertile women. Numerous factors including progestins stimulate pSTAT3 and STAT3 $[9,34]$. The regulation of PSTAT3 

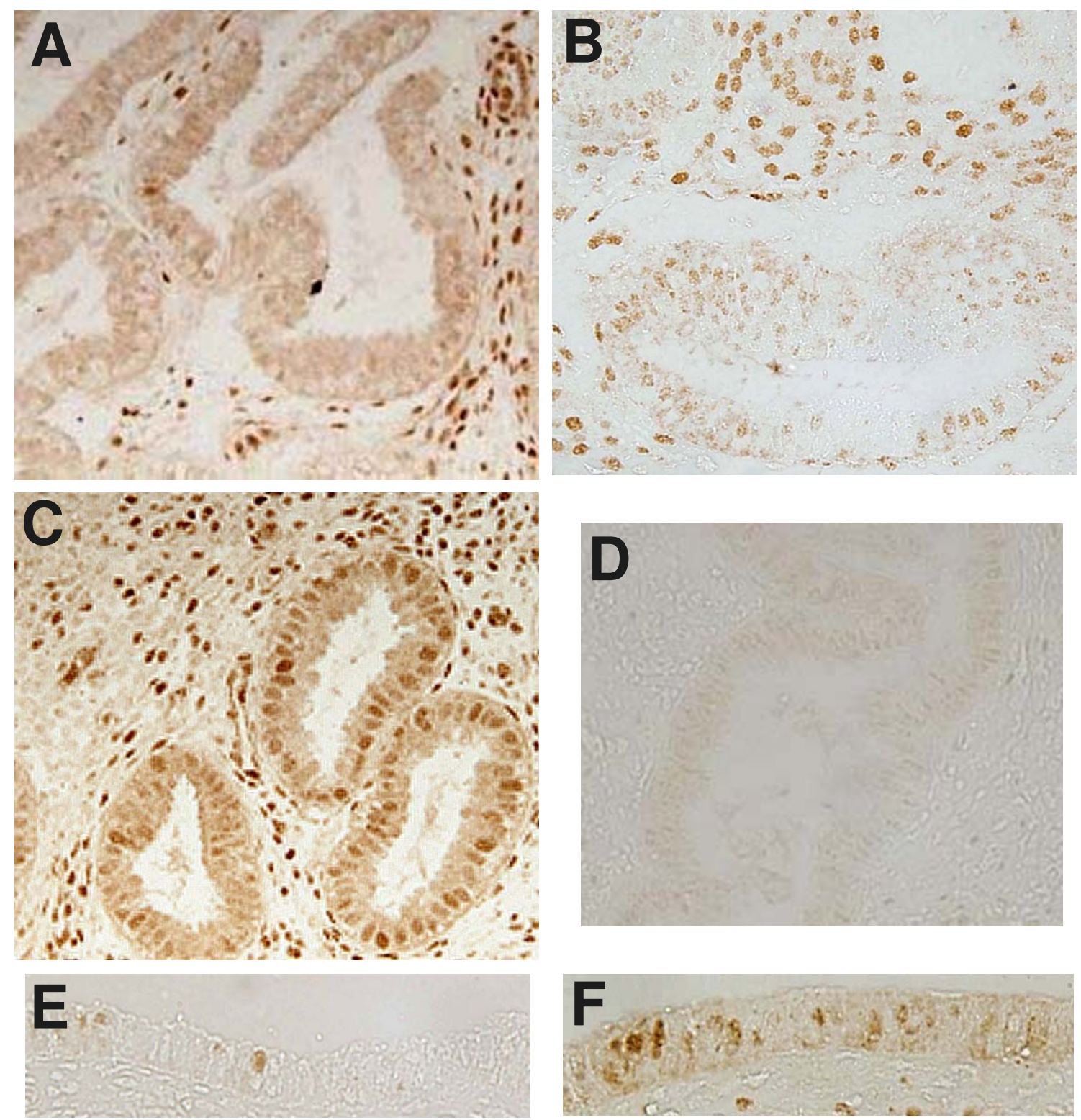

\section{Figure 3}

Photomicrographs representing endometrial PSTAT3 immunostaining in women with primary infertility and fertile women. Magnification $\times 200$. (A and B) PSTAT3 immunostaining of endometrium from women with primary infertility. (A) Day LH+7 (B) Day LH+9. (C) Control fertile women day LH+6, PSTAT3 staining. (D) Day LH+I0 tissue showing negative control for PSTAT3 staining. (E) Infertile women at day LH+8 showing PSTAT3 staining of luminal epithelium (F) Control fertile women at Day LH+7 showing luminal epithelium-pSTAT3.

and STAT3 in the uterine glandular epithelium remain to be elucidated.

Minimal pSTAT3 staining was found in eight of the ten infertile women. If the levels of pSTAT3 in some women was due to reduced STAT3 protein abundance this could result in inadequate LIF and IL-11 action. While LIF was not significantly reduced in the endometrial glands of women with infertility, LIF action could be impaired in women with low glandular pSTAT3. Similarly, some women had moderate to high IL-11 and low PSTAT3 in the glands. This could similarly result in abnormal IL-11 action. Further studies are required to determine the mechanisms of action of IL-11 and LIF in endometrial epithelium. In addition, LIF levels did not differ in uterine glandular epithelium between infertile and fertile women 

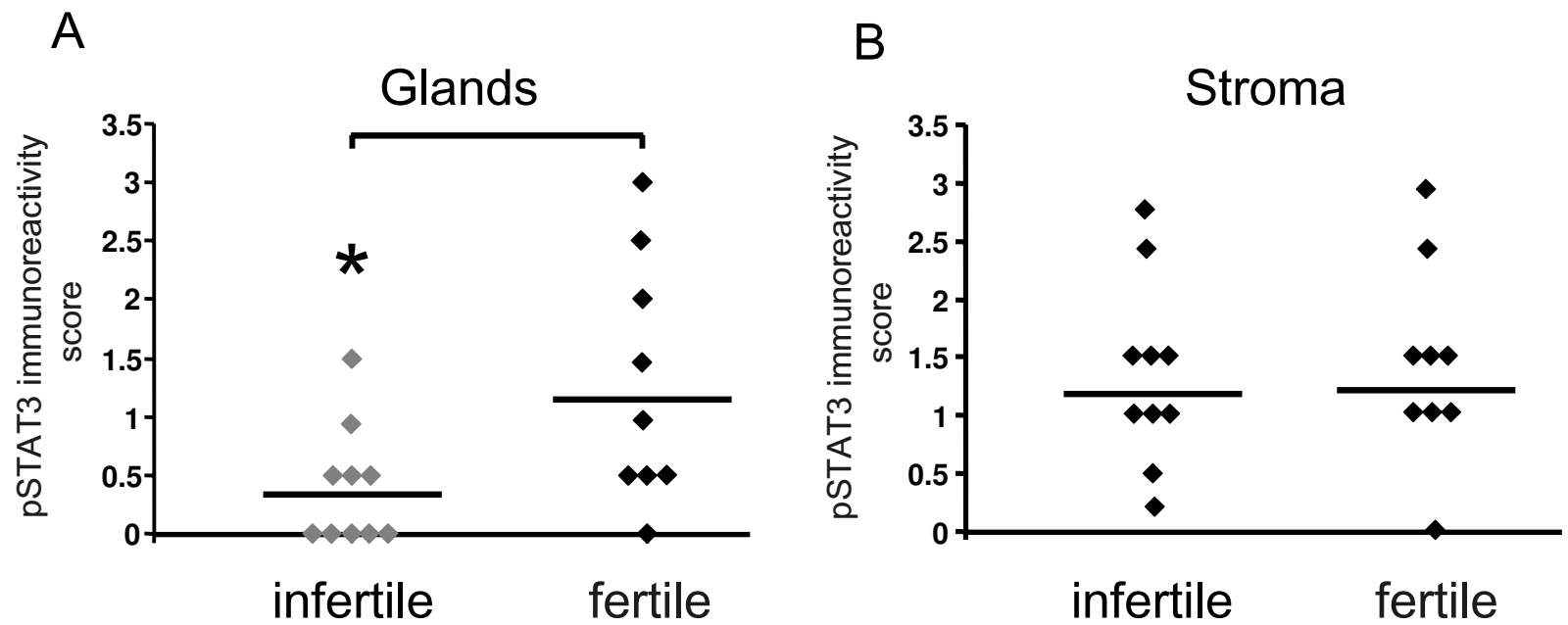

\section{Figure 4}

Immunostaining for PSTAT3 in endometrial glandular epithelium and stroma from normal fertile women and women with primary infertility between days $\mathrm{LH}+6-+10$ of the menstrual cycle. Relative staining intensities are represented as 0 (no staining) to 3 (high). (A) Glandular epithelium. (B) Stroma. Women with primary infertility (infertile) $(n=10)$. Control normal fertile women (fertile) $(n=9)$. Individual data shown for each parameter. Bar represents the mean value. * $P<0.05$ compared to fertile control.

indicating IL-11 and LIF may have different roles in women with unexplained infertility.

In contrast to the present study IL-11, IL-11R $\alpha$ and LIF staining were decreased in glandular epithelial cells in women with endometriosis associated infertility [12]. This suggests the endometrial phenotype of women with primary infertility differs from that of women with endometriosis associated infertility. It is likely that different therapeutic strategies may be necessary to treat endometrial implantation failure depending upon aetiology.

IL-11, pSTAT3, IL-11R $\alpha$ and LIF staining was overall low and patchy or absent in luminal epithelium of both infertile and fertile women. Few tissues contained luminal epithelium making it difficult to analyze the immunostaining in this cellular compartment.

IL-11 like LIF is present in the uterine secretome indicating both could act on the blastocyst or the surface luminal epithelium. The human blastocyst expresses gp130 and LIFR $\alpha$ [35] but whether it also expresses IL-11R $\alpha$ is not known. Although the function of IL-11 and pSTAT3 in endometrial glands needs to be elucidated, unexplained infertility in some women may be due to reduced levels of either IL-11 or pSTAT3.

\section{Conclusion}

Importantly, our study indicates that reduced pSTAT3 and IL-11 are associated with unexplained infertility and play a role in the secretory transformation of uterine glandular epithelium during the receptivity. The factors that regulate the deficiency in IL-11 and pSTAT3 and the functional consequence of this in endometrial epithelium remain to be explored. Understanding the mechanisms of IL-11 and pSTAT3 action in endometrial epithelium may provide new therapeutic strategies for unexplained infertility.

\section{Competing interests}

The authors declare that they have no competing interests that would prejudice the impartiality of this scientific work.

\section{Authors' contributions}

All authors have read and approved the manuscript. ED designed the studies, performed immunohistochemistry for pSTAT3, analysed the data and drafted the manuscript. AS participated in designing the studies and collection of tissues. Y-LT performed immunohistochemistry for IL-11, IL-11Ralpha and LIF and participated in analysing the data. LAS participated in the design of the studies. JRAS participated in design of the studies, recruitment of subjects and collection of tissues. 


\section{Acknowledgements}

We thank Dr Lorraine Robb and the Walter and Eliza Hall Institute of Medical Research, for provision of IL-I I and IL-I IR $\alpha$ antibodies. Support for this project (ED) was provided by the CICCR Program of the Contraceptive Research and Development (CONRAD) Program, Eastern Virginia Medical School (Subproject \#CIG-02-82) and National Health and Medical Research Council of Australia (\#388916). The views expressed by the authors do not necessarily reflect the views of CICCR or CONRAD. LAS was supported by the National Health and Medical Research Council of Australia (\#143798 and \#241000). AS and RS were supported by a grant from The Addenbrooke's Charities fund.

\section{References}

I. Bulletti C, Flamigni C, Giacomucci E: Reproductive failure due to spontaneous abortion and recurrent miscarriage. Hum Reprod Update 1996, 2:1 18-136.

2. Psychoyos A: Hormonal control of ovoimplantation. Vitam Horm 1973, 3 I:201-256.

3. Navot D, Scott RT, Droesch K, Veeck LL, Liu HC, Rosenwaks Z: The window of embryo transfer and the efficiency of human conception in vitro. Fertil Steril I991, 55:1 I4-1 I8.

4. Wilcox AJ, Baird DD, Weinberg CR: Time of implantation of the conceptus and loss of pregnancy. N Engl J Med 1999, 340:1796-1799.

5. Evers JLH: Female subfertility. Lancet 2002, 360:15I-I59.

6. Smith S, Pfeifer SM, Collins J: Diagnosis and management of female infertility. JAMA 2003, 290: $1767-1770$.

7. Lessey BA, Castelbaum AJ, Sawin SW, Sun J: Integrins as markers of uterine receptivity in women with primary unexplained infertility. Fertil Steril 1995, 63(3):535-542.

8. Sharkey AM, Smith SK: The endometrium as a cause of implantation failure. Best Pract Res Clin Obstet Gynaecol 2003, I 7:289-307.

9. Heinrich PC, Behrmann I, Muller-Newen G, Schaper F, Graeve L: Interleukin-6-type cytokine signalling through the gp I30/Jak/ STAT pathway. Biochem J 1998, 334:297-3।4.

10. Cheng JG, Chen JR, Hernandez L, Alvord WG, Stewart CL: Dual control of LIF expression and LIF receptor function regulate Stat3 activation at the onset of uterine receptivity and embryo implantation. Proc Natl Acad Sci USA 200 I, 98:8680-8685.

II. Levy DE, Lee CK: What does Stat3 do? J Clin Invest 2002, 109:1143-1148.

12. Dimitriadis E, Stoikos C, Tan YL, Salamonsen LA: Interleukin II signalling components signal transducer and activator of transcription 3 (STAT3) and suppressor of cytokine signalling 3 (SOCS3) regulate human endometrial stromal cell differentiation. Endocrinology 2006, 147:3809-38I7.

13. Wang H, Dey SK: Roadmap to embryo implantation: clues from mouse models. Nat Rev Genet 2006, 7:185-199.

14. Bilinski P, Roopenian D, Gossler A: Maternal IL-I IRalpha function is required for normal decidua and fetoplacental development in mice. Genes Dev 1998, 1 2:2234-2243.

15. Robb L, Li R, Hartley L, Nandurkar HH, Koentgen F, Begley CG: Infertility in female mice lacking the receptor for interleukin $\mathrm{II}$ is due to a defective uterine response to implantation. Nat Med 1998, 4:303-308.

16. Stewart CL, Kaspar P, Brunet LJ, Bhatt H, Gadi I, Kontgen F, Abbondanzo S): Blastocyst implantation depends on maternal expression of leukaemia inhibitory factor. Nature 1992, 359:76-79.

17. Ernst M, Inglese M, Waring P, Campbell IK, Bao S, Clay FJ, Alexander WS, Wicks IP, Tarlinton DM, Novak U, Heath JK, Dunn AR: Defective gp I 30-mediated signal transducer and activator of transcription (STAT) signalling results in degenerative joint disease, gastrointestinal ulceration, and failure of uterine implantation. J Exp Med 200I, 194: 189-203.

18. Catalano RD, Johnson MH, Campbell EA, Charnock-Jones DS, Smith SK, Sharkey AM: Inhibition of Stat3 activation in the endometrium prevents implantation: A nonsteroidal approach to contraception. Proc Natl Acad Sci USA 2005, I 02:8585-8590.

19. Nakamura H, Kimura T, Koyama S, Ogita K, Tsutsui T, Shimoya, Taniguchi T, Koyama M, Kaneda Y, Murata Y: Mouse model of human infertility: transient and local inhibition of endometrial
STAT-3 activation results in implantation failure. FEBS Lett 2006, 580:2717-2722.

20. Robb L, Dimitriadis E, Li R, Salamonsen LA: Leukaemia inhibitory factor and interleukin-I I: cytokines with key roles in implantation. J Reprod Immunol 2002, 57:129-I4I.

21. Dimitriadis E, White CA, Jones RL, Salamonsen LA: Cytokines, chemokines and growth factors in endometrium related to implantation. Hum Reprod Update 2005, I I:6 13-630.

22. Cullinan EB, Abbondanzo SJ, Anderson PS, Pollard JW, Lessey BA, Stewart CL: Leukaemia inhibitory factor (LIF) and LIF receptor expression in human endometrium suggests a potential autocrine/paracrine function in regulating embryo implantation. Proc Natl Acad Sci USA 1996, 93:3। I 5-3I20.

23. Dimitriadis E, Salamonsen L, Robb L: Expression of interleukin- I I during the human menstrual cycle: coincidence with stromal cell decidualisation and relationship to leukaemia inhibitory factor and prolactin. Mol Hum Reprod 2000, 6:907-9/4.

24. Cork BA, Li TC, Warren MA, Laird SM: Interleukin-I I (IL-I I) in human endometrium: expression throughout the menstrual cycle and the effects of cytokines on endometrial IL- I I production in vitro. J Reprod Immunol 200I, 50:3-17.

25. Dimitriadis E, Stoikos C, Stafford-Bell M, Clark I, Paiva P, Kovacs G, Salamonsen LA: Interleukin- I I, IL-I I receptoralpha and leukaemia inhibitory factor are dysregulated in endometrium of infertile women with endometriosis during the implantation window. J Reprod Immunol 2006, 69:53-64.

26. Sherwin JR, Smith SK, Wilson A, Sharkey AM: Soluble gp I 30 is upregulated in the implantation window and shows altered secretion in patients with primary unexplained infertility. $J$ Clin Endocrinol Metab 2002, 87:3953-3960.

27. Karpovich N, Chobotova K, Carver J, Heath JK, Barlow D, Mardon $\mathrm{HJ}$ : Expression and function of interleukin-I I and its receptor alpha in the human endometrium. Mol Hum Reprod 2003, 9:75-80.

28. Tsai HD, Chang CC, Hsieh YY, Lo HY: Leukaemia inhibitory factor expression in different endometrial locations between fertile and infertile women throughout different menstrual phases. J Assist Reprod Genet 2000, 17:415-4I8.

29. Laird SM, Tuckerman EM, Dalton CF, Dunphy BC, Li TC, Zhang X: The production of leukaemia inhibitory factor by human endometrium: presence in uterine flushings and production by cells in culture. Hum Reprod 1997, I 2:569-574.

30. Ledee-Bataille N, Lapree-Delage G, Taupin JL, Dubanchet S, Frydman $R$, Chaouat G: Concentration of leukaemia inhibitory factor (LIF) in uterine flushing fluid is highly predictive of embryo implantation. Hum Reprod 2002, 17:213-218.

31. Mikolajczyk M, Wirstlein P, Skrzypczak J: Leukaemia inhibitory factor and interleukin II levels in uterine flushings of infertile patients with endometriosis. Hum Reprod 2006, 21:3054-3058.

32. Makkar G, Ng EH, Yeung WS, Ho PC: Reduced expression of interleukin- $I I$ and interleukin- 6 in the periimplantation endometrium of excessive ovarian responders during in vitro fertilization treatment. J Clin Endocrinol Metab 2006, 91:318I-3188.

33. Noyes RW, Hertig AT, Rock J: Dating the Endometrial Biopsy. Fertil Steril 1950, I:3-25.

34. Proietti C, Salatino M, Rosemblit C, Carnevale R, Pecci A, Kornblihtt AR, Molinolo AA, Frahm I, Charreau EH, Schillaci R, Elizalde PV: Progestins induce transcriptional activation of signal transducer and activator of transcription 3 (Stat3) via a Jak- and Srcdependent mechanism in breast cancer cells. Mol Cell Biol 2005, 25:4826-4840.

35. Sharkey AM, Dellow K, Blayney M, Macnamee M, Charnock-Jones S, Smith SK: Stage-specific expression of cytokine and receptor messenger ribonucleic acids in human preimplantation embryos. Biol Reprod 1995, 53:974-98I. 